\title{
ANALISIS FAKTOR-FAKTOR YANG BERHUBUNGAN DENGAN PEMANFAATAN PELAYANAN KESEHATAN PADA PESERTA JAMINAN KESEHATAN NASIONAL DI WILAYAH KERJA PUSKESMAS PAYAKABUNG, KABUPATEN OGAN ILIR
}

\author{
Bambang Irawan, Asmaripa Ainy
}

Fakultas Kesehatan Masyarakat Universitas Sriwijaya

\author{
ANALYSIS OF ASSOCIATED FACTORS WITH HEALTH SERVICES UTILIZATION FOR \\ NATIONAL HEALTH INSURANCE PARTICIPANTS AT WORKING AREA OF \\ PAYAKABUNG HEALTH CENTER, OGAN ILIR DISTRICT
}

\begin{abstract}
Background: Health center provides primary health care for national health insurance participants. Based on data from Ogan ilir district health office in 2017, the lowest outpatients visit for national health insurance patients occurred at Payakabung health center (650 patients). The aim of this study was to analyze associated factors with health services utilization at working area of Payakabung health center

Methods: This was a cross sectional study using simple random sampling technique with total sample was 112 respondents.

Results: The results of the study illustrated that only 43,8\% respondents utilized health services. The most of respondents have characteristics as follow: age $\leq 46$ years (60,7\%), female (59,8\%), low education (76,8\%), employment $(66,1 \%)$, having good perception regarding health officers attitude $(61,6 \%)$, having good perception regarding national health insurance $(55,4 \%)$, close to health center $(67,9 \%)$ and having positive perception regarding pain (58,9\%). There were correlation between age variable ( $p$-value $<0,0001)$, sex ( $p$ value $=0,016)$, perception regarding national health insurance ( $p$-value=0,039), service accessibility ( $p$ value $=<0,0001$ ) and health services utilization for national health insurance participants at working area of Payakabung health center.

Conclusion: There were four variables correlated significantly with health services utilization (age, gender, perception regarding national health insurance, and service accessability). It is suggested that good understanding concerning national health insurance programs among society need to be improved in order to effectiveness of health service at health center .
\end{abstract}

Keywords: Utilization, health service, national health insurance, public health center

\begin{abstract}
ABSTRAK
Latar Belakang: Puskesmas menyediakan layanan kesehatan bagi peserta Jaminan Kesehatan Nasional (JKN). Berdasarkan data dari dinas kesehatan kabupaten Ogan Ilir tahun 2017, kunjungan pasien rawat jalan terendah terjadi di Puskesmas Payakabung sebesar 650 pasien. Tujuan penelitian ini adalah untuk menganalisis faktor-faktor yang berhubungan dengan pemanfaatan pelayanan kesehatan pada peserta JKN di wilayah kerja Puskesmas Payakabung.

Metode: Jenis penelitian ini adalah cross sectional menggunakan teknik pengambilan sampel simple random sampling dengan jumlah sampel sebanyak 112 orang.

Hasil Penelitian: Hasil penelitian menunjukkan bahwa hanya sebesar 43,8\% responden yang memanfaatkan layanan kesehatan. Paling banyak responden menunjukkan karakteristik sebagai berikut: usia $\leq 46$ tahun $(60,7 \%)$, perempuan $(59,8 \%)$, pendidikan rendah $(76,8 \%)$, bekerja $(66,1 \%)$, memiliki persepsi yang baik mengenai sikap petugas $(61,6 \%)$, memiliki persepsi yang baik mengenai JKN $(55,4 \%)$, jarak antara rumah dan puskesmas dekat $(67,9 \%)$ and memiliki persepsi positif mengenai sakit $(58,9 \%)$. Ada hubungan signifikan antara variable usia ( $\mathrm{p}$-value $<0,0001$ ), jenis kelamin ( $\mathrm{p}$-value $=0,016$ ), persepsi mengenai JKN ( $\mathrm{p}$-value $=0,039)$, aksesibilitas layanan (p-value $<0,0001)$ dengan pemanfaatan layanan kesehatan bagi peserta JKN di wilayah kerja Puskesmas Payakabung.

Kesimpulan: Berdasarkan uji statistik, terdapat empat variabel yang berhubungan secara signifikan dengan pemanfaatan layanan kesehatan (usia, jenis kelamin, persepsi mengenai JKN, aksesibilitas layanan).
\end{abstract}

Alamat Koresponding: Asmaripa Ainy, Fakultas Kesehatan Masyarakat Universitas Sriwijaya, Jl. Raya Palembang-Prabumilih km. 32, Indralaya, Kabupaten Ogan Ilir, Sumatera Selatan, Email: asmaripa_ainy@fkm.unsri.ac.id 
Disarankan agar pemahaman mengenai program JKN bagi masyarakat sangat diperlukan untuk efektifitas layanan kesehatan di puskesmas.

Kata Kunci: Utilisasi, layanan kesehatan, jaminan kesehatan nasional, puskesmas

\section{PENDAHULUAN}

Puskesmas dan JKN adalah dua hal yang saling berkaitan dan tidak bisa dipisahkan dalam sistem pelayanan kesehatan di Indonesia. Pemberian layanan kesehatan yang baik di puskesmas akan memungkinkan banyak peserta JKN yang memanfaatkan pelayanan kesehatan, hal ini juga berdampak sebaliknya jika pelayanan kesehatan di puskesmas dirasa buruk atau kurang baik. ${ }^{1}$ Penelitian mengenai faktor-faktor yang mempengaruhi pemanfaatan pelayanan kesehatan di Puskesmas Sumber Rejo, Balikpapan menyebutkan bahwa faktor konsumen baik dari segi usia, pendidikan, pekerjaan, ketersedian tenaga kesehatan, jarak ke lokasi pelayanan, perilaku petugas, dan persepsi sakit dapat mempengaruhi pasien untuk memanfaatkan pelayanan kesehatan. ${ }^{2}$ Pada penelitian lain, perilaku petugas juga menunjukkan hubungan yang signifikan dengan pemanfaatan pelayanan kesehatan oleh pasien rawat inap di puskesmas. ${ }^{3}$ Selanjutnya, lokasi puskesmas yang jauh dan akses jalan menuju puskesmas yang buruk dapat mempengaruhi minat untuk memanfaatkan pelayanan kesehatan di puskesmas. ${ }^{4}$

Berdasarkan Profil Dinas Kesehatan Kabupaten Ogan Ilir Tahun 2017, jumlah kepesertaan JKN kategori PBI terendah adalah di wilayah kerja Puskesmas Payakabung Kabupaten Ogan Ilir yakni sebanyak 1.712 orang. Berdasarkan laporan BPJS Kesehatan Cabang Palembang tahun 2017, kunjungan peserta BPJS Kesehatan di wilayah kerja Puskesmas Payakabung Kabupaten Ogan Ilir mengalami kondisi yang fluktuatif setiap bulannya dan kecenderungannya rendah. Sehingga diperlukan penelitian untuk menganalisis faktor-faktor apa saja yang berhubungan dengan pemanfaatan pelayanan kesehatan di Puskesmas Payakabung oleh peserta JKN. Diharapkan dengan penelitian ini pemanfaatan pelayanan kesehatan di Puskesmas Payakabung dapat efektif sehingga mampu menjadi unit pelayanan kesehatan tingkat pertama terbaik yang mampu bersaing dengan pelayanan kesehatan lainnya. Penelitian ini bertujuan untuk menganalisis faktor-faktor yang berhubungan dengan pemanfaatan pelayanan kesehatan pada peserta JKN di wilayah kerja Puskesmas Payakabung Kabupaten Ogan Ilir.

\section{METODE}

Desain penelitian yang digunakan pada penelitian ini adalah cross sectional. Populasi dalam penelitian ini adalah seluruh peserta JKN di wilayah kerja Puskesmas Payakabung Kabupaten Ogan Ilir berjumlah 1.712 peserta pada tahun 2017 dengan sampel 112 orang. Cara pengambilan sampel dilakukan dengan menggunakan metode simple random sampling dengan teknik pemetaan wilayah. Jenis data yang digunakan pada penelitian ini merupakan data primer karena data diperoleh langsung dari hasil pengisian kuesioner yang disebar pada responden di wilayah kerja Puskesmas Payakabung Kabupaten Ogan Ilir. Analisis data penelitian ini menggunakan analisis univariat dan bivariat dengan uji chi square.

\section{HASIL PENELITIAN Pemanfaatan Pelayanan Kesehatan}

Distribusi frekuensi faktor yang mempengaruhi pemanfaatan pelayanan kesehatan pada peserta JKN di wilayah kerja Puskesmas Payakabung dapat dilihat pada tebel berikut 
Tabel 1.

Distribusi Responden Berdasarkan Pemanfaatan Pelayanan Kesehatan pada Peserta JKN di Wilayah Kerja Puskesmas Payakabung Tahun 2018

\begin{tabular}{|c|c|c|}
\hline \multirow{2}{*}{ Variabel } & \multicolumn{2}{|c|}{ Total Responden } \\
\hline & $\mathbf{n}$ & $\%$ \\
\hline \multicolumn{3}{|c|}{ Variabel Dependen } \\
\hline \multicolumn{3}{|c|}{ Pemanfaatan pelayanan kesehatan } \\
\hline Memanfaatkan & 49 & 43,8 \\
\hline Tidak memanfaatkan & 63 & 56,2 \\
\hline \multicolumn{3}{|l|}{ Variabel Independen } \\
\hline \multicolumn{3}{|l|}{ Usia } \\
\hline$>46$ Tahun & 44 & 39,3 \\
\hline$\leq 46$ Tahun & 68 & 60,7 \\
\hline \multicolumn{3}{|l|}{ Jenis kelamin } \\
\hline Perempuan & 67 & 59,8 \\
\hline Laki-laki & 45 & 40,2 \\
\hline \multicolumn{3}{|l|}{ Tingkat pendidikan } \\
\hline Tinggi & 26 & 23,2 \\
\hline Rendah & 86 & 76,8 \\
\hline \multicolumn{3}{|l|}{ Status pekerjaan } \\
\hline Bekerja & 74 & 66,1 \\
\hline Tidak bekerja & 38 & 33,9 \\
\hline \multicolumn{3}{|c|}{ Persepsi mengenai sikap petugas } \\
\hline Baik & 69 & 61,6 \\
\hline Kurang & 43 & 38,4 \\
\hline \multicolumn{3}{|l|}{ Persepsi mengenai JKN } \\
\hline Baik & 62 & 55,4 \\
\hline Kurang & 50 & 44,6 \\
\hline \multicolumn{3}{|l|}{ Aksesibilitas layanan } \\
\hline Dekat & 76 & 67,9 \\
\hline Jauh & 36 & 32,1 \\
\hline \multicolumn{3}{|l|}{ Persepsi sakit } \\
\hline Positif & 66 & 58,9 \\
\hline Negatif & 46 & 41,1 \\
\hline
\end{tabular}

Sebesar $43,8 \%$ responden penelitian memanfaatkan layanan kesehatan di Puskesmas Payakabung, yang artinya sebagian besar responden dalam penelitian ini tidak memanfaatkan pelayanan kesehatan (56,2\%). Sebagian besar responden memiliki karakteristik sebagai berikut: usia $\leq 46$ tahun
$(60,7 \%)$, perempuan $(59,8 \%)$, pendidikan rendah $(76,8 \%)$, bekerja $(66,1 \%)$, persepsi baik mengenai sikap petugas $(61,6 \%)$, persepsi baik mengenai JKN $(55,4 \%)$, jarak ke puskesmas dekat $(67,9 \%)$ dan persepsi sakit yang positif $(58,9 \%)$. 
Tabel 2.

Hubungan antara Variabel Independen dengan Pemanfaatan Pelayanan Kesehatan bagi Peserta JKN di Wilayah Kerja Puskesmas Payakabung Tahun 2018

\begin{tabular}{|c|c|c|c|c|c|c|}
\hline \multirow{3}{*}{ Variabel } & \multicolumn{4}{|c|}{ Pemanfaatan Pelayanan Kesehatan } & \multirow{3}{*}{ p-value } & \multirow{3}{*}{$\begin{array}{c}\text { PR } \\
(95 \% \mathrm{CI})\end{array}$} \\
\hline & \multicolumn{2}{|c|}{ Memanfaatkan } & \multicolumn{2}{|c|}{$\begin{array}{c}\text { Tidak } \\
\text { Memanfaatkan }\end{array}$} & & \\
\hline & $\mathbf{N}$ & $\%$ & $\mathbf{n}$ & $\%$ & & \\
\hline \multicolumn{7}{|l|}{ Usia } \\
\hline$>46$ Tahun & 29 & 65,9 & 15 & 34,1 & \multirow{2}{*}{$<0,0001$} & 2,241 \\
\hline$\leq 46$ Tahun & 20 & 29,4 & 48 & 70,6 & & $(1,465-3,428)$ \\
\hline \multicolumn{7}{|l|}{ Jenis kelamin } \\
\hline Perempuan & 36 & 53,7 & 31 & 46,3 & \multirow{2}{*}{0,016} & 1,860 \\
\hline Laki-laki & 13 & 28,9 & 32 & 71,1 & & $(1,118-3,096)$ \\
\hline \multicolumn{7}{|l|}{$\begin{array}{l}\text { Tingkat } \\
\text { pendidikan }\end{array}$} \\
\hline Tinggi & 10 & 38,5 & 16 & 61,5 & \multirow{2}{*}{0,693} & 0,848 \\
\hline Rendah & 39 & 45,3 & 47 & 54,7 & & $(0,495-1,454)$ \\
\hline \multicolumn{7}{|c|}{ Status pekerjaan } \\
\hline Bekerja & 28 & 37,8 & 46 & 62,2 & \multirow{2}{*}{0,119} & 0,685 \\
\hline Tidak bekerja & 21 & 55,3 & 17 & 44,7 & & $(0,455-1,030)$ \\
\hline \multicolumn{7}{|c|}{$\begin{array}{l}\text { Persepsi mengenai } \\
\text { sikap petugas }\end{array}$} \\
\hline Baik & 35 & 50,7 & 34 & 49,3 & \multirow{2}{*}{0,091} & 1,558 \\
\hline Kurang & 14 & 32,6 & 29 & 67,4 & & $(0,955-2,541)$ \\
\hline \multicolumn{7}{|c|}{ Persepsi mengenai } \\
\hline \multicolumn{7}{|c|}{ JKN } \\
\hline Baik & 33 & 53,2 & 29 & 46,8 & \multirow{2}{*}{0,039} & 1,663 \\
\hline Kurang & 16 & 32,0 & 34 & 68,0 & & $(1,043-2,652)$ \\
\hline \multicolumn{7}{|l|}{ Aksesibilitas } \\
\hline \multicolumn{7}{|l|}{ layanan } \\
\hline Dekat & 18 & 23,7 & 58 & 76,3 & \multirow{2}{*}{$<0,0001$} & 0,275 \\
\hline Jauh & 31 & 86,1 & 5 & 13,9 & & $(0,180-0,420)$ \\
\hline \multicolumn{7}{|l|}{$\begin{array}{l}\text { Persepsi } \\
\text { sakit }\end{array}$} \\
\hline Positif & 31 & 47,0 & 35 & 53,0 & \multirow{2}{*}{0,529} & 1,200 \\
\hline Negatif & 18 & 39,1 & 28 & 60,9 & & $(0,771-1,868)$ \\
\hline
\end{tabular}

Ada empat variabel yang berhubungan dengan pemanfaatan pelayanan kesehatan bagi peserta JKN di wilayah kerja Puskesmas Payakabung yakni: usia ( $p$-value $=<0,0001$ ), jenis kelamin ( $p$-value $=0,016)$, persepsi mengenai JKN $\quad(p$-value $=0,039) \quad$ dan aksesibilitas layanan ( $p$-value $=<0,0001)$. Dari hasil analisis, diperoleh bahwa nilai PR pada variabel usia $(2,241)$, jenis kelamin $(1,860)$, persepsi mengenai JKN (1,663), aksesibilitas layanan $(0,275)$. Pada populasi umum, dengan CI $95 \%$ bahwa peluang yang berusia $>46$ tahun untuk memanfaatkan pelayanan kesehatan di Puskesmas Payakabung antara 1,465 dan 3,428 dibandingkan kelompok usia $\leq 46$ tahun. Perempuan memanfaatkan pelayanan kesehatan di Puskesmas Payakabung antara 1,118 dan 3,096 dibandingkan laki-laki. Persepsi baik mengenai JKN memiliki peluang untuk memanfaatkan pelayanan kesehatan di Puskesmas Payakabung antara 1,043 dan 2,652 dibandingkan persepsi kurang tentang JKN. Responden yang rumahnya dekat dengan Puskesmas Payakabung memiliki peluang untuk memanfaatkan pelayanan kesehatan antara 0,180 dan 0,420 dibandingkan dengan responden yang jarak rumahnya jauh dari puskesmas.

\section{PEMBAHASAN}

Hubungan Usia dengan Pemanfaatan Pelayanan Kesehatan pada Peserta JKN di Wilayah Kerja Puskesmas Payakabung

Pada teori Health Service Use yang juga menyebutkan bahwa usia adalah salah 
satu faktor predisposisi atau internal yang mempengaruhi perilaku seseorang tersebut untuk melakukan pemanfaatan pelayanan kesehatan. ${ }^{5}$ Semakin tua seseorang maka daya tahan tubuh seseorang akan semakin menurun dan pada usia lansia derajat penyakit yang dialami akan semakin berat maka kecenderungan pada usia lansia akan semakin banyak membutuhkan pelayanan kesehatan demi kesembuhan penyakit tersebut. Hasil di atas juga sejalan dengan penelitian lainnya yang menyatakan adanya pengaruh usia untuk memanfaatkan pelayanan kesehatan. $^{6}$ Usia lansia akan sering mendatangi pelayanan kesehatan meskipun ada beberapa kelompok bukan kategori usia lansia juga sering memanfaatkan pelayanan kesehatan. ${ }^{7}$

$$
\text { Peneliti juga menemukan }
$$

kecenderungan usia > 46 tahun lebih banyak memanfaatkan pelayanan kesehatan dibandingkan usia $\leq 46$ tahun. Dari beberapa responden menyebutkan bahwa pada usia $>46$ tahun harus memperhatikan kesehatan dikarenakan kebanyakan dari orang yang berusia > 46 tahun adalah tulang punggung keluarga sehingga ekonomi keluarga akan buruk bila meraka jatuh sakit. Namun sebaliknya pada usia $\leq 46$ tahun tidak terlalu memperhatikan kesehatan karena menganggap sakit itu adalah hal yang biasa. Meskipun peserta JKN untuk golongan PBI dapat memanfaatkan pelayanan kesehatan secara gratis, kenyataannya mereka masih kurang menggunakan pelayanan tersebut.

\section{Hubungan Jenis Kelamin dengan Pemanfaatan Pelayanan Kesehatan pada Peserta JKN di Wilayah Kerja Puskesmas Payakabung}

Jenis kelamin dapat mempengaruhi dalam pengambilan keputusan untuk melakukan pencarian pengobatan. ${ }^{8}$ Hal ini dikarenakan perempuan membutuhkan pelayanan kesehatan khusus seperti pelayanan kesehatan kehamilan dan penyakit-penyakit spesifik yang mengharuskan perempuan memanfaatkan pelayanan kesehatan. Studi lain menyebutkan bahwa jenis kelamin tidak mempengaruhi orang untuk dapat memanfaatan pelayanan kesehatan. ${ }^{9}$ Baik lakilaki maupun perempuan memiliki risiko yang sama untuk memanfaatkan pelayanan kesehatan di puskesmas dan faktor perilaku atau kebiasaan setempat yang bisa membedakan orang itu akan memanfaatkan pelayanan kesehatan atau tidak. ${ }^{10}$

\section{Hubungan Tingkat Pendidikan dengan Pemanfaatan Pelayanan Kesehatan pada Peserta JKN di Wilayah Kerja Puskesmas Payakabung}

Berdasarkan penelitian menunjukkan bahwa tingkat pendidikan tidak mempengaruhi dalam pemanfaatan pelayanan kesehatan tetapi banyak faktor lainnya yang dapat mempengaruhi pemanfaatan pelayanan kesehatan, salah satunya adalah era global. ${ }^{11,12}$ Era global dapat meningkatkan pengetahuan secara instan melalui kemudahan akses layanan internet. Pendidikan di masa yang akan datang, bukan hanya sekolah satusatunya penentu tingkat pengetahuan akan tetapi jaringan informasi yang memungkinkan berinteraksi dan berkolaborasi. ${ }^{13}$ Walaupun demikian, tingkat pendidikan juga dapat mempengaruhi pemanfaatan pelayanan kesehatan dikarenakan dengan pendidikan yang tinggi maka seseorang akan mempunyai pengetahuan yang tinggi dibandingkan dengan seseorang yang berpendidikan rendah. ${ }^{14}$ Sehingga orang dengan pendidikan yang lebih tinggi diharapkan mampu memahami pentingnya untuk memelihara kesehatan diri atau orang sekitarnya.

Hubungan Status Pekerjaan dengan Pemanfaatan Pelayanan Kesehatan pada Peserta JKN di Wilayah Kerja Puskesmas Payakabung

Hasil penelitian menunjukkan bahwa status pekerjaan tidak berhubungan dengan pemanfaatan pelayanan kesehatan di Puskesmas Payakabung. Dalam penelitian 
lainnya juga menyebutkan bahwa status pekerjaan tidak ada hubungan yang berarti pada pemanfaatan pelayanan kesehatan. ${ }^{15}$ Meskipun berbeda berdasarkan hukum Engel yang menyatakan bahwa rumah tangga yang mempunyai pendapatan rendah akan mengeluarkan sebagian besar pendapatan mereka untuk kebutuhan pokok dan sebaliknya orang yang mempunyai pendapatan yang tinggi akan membelanjakan sebagian kecil untuk kebutuhan pokok. ${ }^{16} \mathrm{Pada}$ kelompok orang yang bekerja ataupun tidak memiliki pekerjaan tidak akan selalu berhubungan dengan pemanfaatan pelayanan kesehatan karena pola pikir dan motivasi yang cenderung berubah-ubah membuat seseorang akan memilih pengobatan atau pelayanan kesehatan lainnya.

\section{Hubungan Persepsi Mengenai Sikap Petugas dengan Pemanfaatan Pelayanan Kesehatan pada Peserta JKN di Wilayah Kerja Puskesmas Payakabung}

Tindakan atau cara petugas dalam melakukan pelayanan merupakan hal yang sangat mempengaruhi pasien dalam pemanfaatan layanan. ${ }^{17-18}$ Adanya perlakuan yang baik dan penuh perhatian menjadi suatu daya tarik tersendiri dalam pemberian pelayanan kepada pasien. Hal ini menumbuhkan pengaruh psikologis dan motivasi bagi pasien untuk memanfaatan pelayanan kesehatan yang diberikan. ${ }^{19}$

Pada penelitian ini ditemukan bahwa para petugas kesehatan telah bersikap baik sehingga sebagian besar responden memiliki persepsi baik terhadap layanan yang diberikan petugas. Hal ini dilihat dari hasil jawaban setuju responden dengan sikap komunikatif petugas kesehatan tersebut dan sikap petugas yang sopan. Akan tetapi, masih ada jawaban yang kurang baik mengenai sikap petugas yang terkesan masih membandingkan status sosial peserta JKN. Masyarakat masih memilih untuk memanfaatkan pelayanan kesehatan di Puskesmas Payakabung dikarenakan tidak mempunyai pilihan lain untuk memilih layanan kesehatan lainya. Karena mereka telah menjadi peserta JKN yang biaya berobatnya ditanggung oleh pemerintah atau gratis. Hal ini membuat persepsi mengenai sikap petugas kesehatan tidak mempengaruhi dalam pemanfaatan pelayanan kesehatan.

\section{Hubungan Persepsi Mengenai JKN dengan Pemanfaatan Pelayanan Kesehatan pada Peserta JKN di Wilayah Kerja Puskesmas Payakabung}

Hasil penelitian ini menunjukkan adanya hubungan antara persepsi mengenai JKN dengan pemanfaatan pelayanan kesehatan. Persepsi yang baik mengenai JKN akan mendorong masyarakat untuk memanfaatkan pelayanan kesehatan. $^{20-21}$ Persepsi masyarakat yang kurang baik mengenai JKN pada penelitian ini terkait dengan alur pelayanan yang dirasakan sulit serta lamanya waktu tunggu untuk mendapatkan pelayanan kesehatan. Hal ini menyebabkan responden peserta JKN memiliki persepsi untuk tidak memanfaatkan pelayanan kesehatan di Puskesmas Payakabung.

\section{Hubungan Aksesibilitas Layanan dengan Pemanfaatan Pelayanan Kesehatan pada Peserta JKN di Wilayah Kerja Puskesmas Payakabung}

Sesuai dengan teori utilitas pelayanan kesehatan yang menjelaskan bahwa keinginan seseorang untuk memanfaatkan pelayanan kesehatan juga ditentukan oleh faktor pendukung yakni salah satunya adalah jarak atau aksesibilitas layanan kesahatan. ${ }^{22}$ Dengan kondisi jalan yang buruk dan sulitnya akses ke pelayanan kesehatan membuat seseorang tidak mau memanfaatkan pelayanan kesehatan tersebut. Beda halnya dengan teori Health Belief Model yang menyatakan bahwa dalam 
faktor struktur yang berkaitan dengan akses ke pelayanan kesehatan akan cenderung mempengaruhi keputusan seseorang untuk memanfaatkan atau tidak memanfaatkan pelayanan kesehatan. ${ }^{23-24}$ Peserta JKN yang memiliki rumah dengan jarak tempuh yang jauh dari puskesmas Payakabung tetap cenderung banyak memanfaatkan pelayanan kesehatan karena tidak ada pilihan pelayanan kesehatan yang lain.

\section{Hubungan Persepsi Sakit dengan Pemanfaatan Pelayanan Kesehatan pada Peserta JKN di Wilayah Kerja Puskesmas Payakabung}

Persepsi sakit tidak ada hubungan dengan pemanfaatan pelayanan kesehatan bagi peserta JKN di Puskesmas. ${ }^{25-26}$ Kenyataannya, masyarakat cenderung baru mau mencari pengobatan ke pelayanan kesehatan bila keadaan dirinya benar-benar tidak dapat berbuat apa-apa. Persepsi masyarakat yang keliru dalam menyikapi sakit menyebabkan kurang memanfaatkan saranasarana kesehatan yang ada meskipun puskesmas berada di wilayah tempat tinggalnya. Persepsi sakit yang keliru akan mengakibatkan pemanfaatan kesehatan di puskesmas rendah. $^{27}$

Hal berbeda ditemukan pada masyarakat Payakabung yang lebih banyak memanfaatkan pelayanan kesehatan adalah masyarakat dengan persepsi sakit yang positif artinya masyarakat Payakabung sendiri memahami bahwa kesehatan merupakan prioritas pertama dan mengerti akan tindakan untuk memanfaatkan pelayanan kesehatan jika sakit. Meskipun begitu masih ada masyarakat

\section{DAFTAR PUSTAKA}

1. Triwardani Y. Faktor-Faktor yang Berhubungan dengan Kepuasan Pasien BPJS pada Pelayanan di Puskesmas Pamulang. Skripsi UIN Syarif Hidayatullah Jakarta. 2017. masih kurang dalam menyikapi rasa sakit sehingga masih membiarkan gejala-gejala sakit yang diderita dan mengandalkan obatobatan di warung jika sakit. Persepsi sakit tidak berhubungan dengan pemanfaatan pelayanan kesehatan karena pada dasarnya program JKN khusus PBI ini sendiri mempunyai layanan gratis sehingga masyarakat mau memanfaatkannya.

\section{KESIMPULAN DAN SARAN}

Masyarakat peserta JKN di wilayah kerja Puskesmas Payakabung yang memanfaatkan pelayanan kesehatan di puskesmas lebih sedikit dibandingkan yang tidak memanfaatkan yakni sebesar $43,8 \%$. Berdasarkan uji statistik, terdapat empat variabel yang berhubungan secara signifikan dengan pemanfaatan layanan kesehatan yakni: usia ( $p$-value $<0,0001$ ), jenis kelamin $(p$-value $=0,016)$, persepsi mengenai JKN ( $p$-value $=0,039)$ dan aksesibilitas layanan ( $p$-value $<0,0001)$.

Disarankan agar pemahaman mengenai program JKN bagi masyarakat sangat diperlukan untuk efektifitas layanan kesehatan di puskesmas. Untuk peneliti selanjutnya disarankan untuk menganalisis variabel-variabel lain misalnya: status perkawinan, jumlah anggota keluarga, sosial budaya, penghasilan dan ketersediaan fasilitas dengan desain penelitian yang berbeda sehingga dapat menggali informasi lebih mendalam tentang faktor-faktor yang mempengaruhi pemanfaatan pelayanan kesehatan oleh masyarakat di Puskesmas Payakabung.

2. Wahyuni N S. Faktor-Faktor yang Berhubungan dengan Pemanfaatan Kesehatan di Puskesmas Sumber Rejo Kota Balikpapan Provinsi Kalimantan Timur Tahun 2012. Skripsi Universitas Indonesia. 2012.

3. Supardi S., Rini S.H dan Mulyono N. Faktor-Faktor yang Berhubungan dengan 
Kepuasan Pasien Rawat Jalan dan Rawat Inap di Puskesmas (Analisa Data Skrt 2004). Jurnal Bul Panel Kesehatan. 2008; Vol. 36 (3) : 135-144.

4. Nusawakan, AW., Sanifia T.M dan Savnat J. Faktor yang Mempengaruhi Pengambilan Keputusan dalam Penggunaan Layanan Kesehatan pada Wilayah Kerja Puskesmas Tawiri. Jurnal Media Ilmu Kesehatan. 2017; Vol. 6 (2) : 101-110.

5. Andersen R, J Kravits, OW Anderson. Equity In Health Services. Cambridge: Ballinger Publishing Co. 1975.

6. Anggraini. Merry $\mathrm{T}$ dan Afiana $\mathrm{R}$. Hubungan Kepuasan Pasien dengan Minat Pasien dalam Pemanfaatan Ulang Pelayanan Kesehatan pada Praktek Dokter Keluarga. UNIMUS. 2012; Vol. 1 (2) : 54-77.

7. Handayani R., Asmaripa A dan Misnaniarti. Analisis Hubungan antara Dukungan Keluarga Inti (Nuclear Family) dan Pemanfaatan Pelayanan Pemeriksaan Kesehatan Berkala Karyawan Direktorat Produksi PT PUSRI Palembang. Jurnal Ilmu Kesehatan Masyarakat. 2010; Vol. 1. 3081.

8. Yuniar. Akses Pelayanan Kesehatan dan Kejadian Malaria di Provinsi Bengkulu Tahun 2013. Media Litbangkes. 2013; Vol. 23 (4) : 158-164.

9. Rachmawati. St., Darmawansyah dan Muh YA. Faktor-Faktor yang Berhubungan dengan Pemanfaatan Kesehatan di Puskesmas Tamalanrea Kota Makassar. UNHAS. 2014; Vol. 5 (4) : 79-104.

10. Rosyada D F dan Savitri C B. Keikutsertaan Program Kesehatan Lansia Ditinjau dari Biaya Kepuasan Pelayanan dan Harapan Pasien di Puskesmas Nanggulan Kabupaten Kulon Progo. Jurnal Ilmu Kesehatan Masyarakat. 2018; Vol. 9 (1) : 11-20.

11. Marnah., Husaini dan Bahrul I. Analisis Prilaku Masyarakat dalam Pemanfaatan Pelayanan Kesehatan Peserta Program Keluarga Harapan (PKH) di Kecammatan Paminggir. Jurnal Berkala Kesehatan. UNILA. 2016; Vol. 1 (2) : 130-138.
12. Rosdelina. Faktor-Faktor yang Berhubungan dengan Pencarian Pengobatan Balita Penderita Infeksi Pernapasan Akut Studi di Kelurahan Bangetayu Wetan Kecamatan Genuk Tahun 2011. Artikel Ilmiah. UNDIP. 2011; Vol. 1 (5) : 63-79.

13. Saputra H. Pengembangan Mutu Pendidikan Menuju Era Global. Bandung : Diandra Primamitra. 2016.

14. Notoatmodjo S. Pendidikan dan Prilaku Kesehatan. Jakarta : Rineka Cipta. 2013.

15. Delima. 2004. Prilaku Pencarian Pengobatan Balita di Kabupaten Purworejo. Tesis. UGM. 2003.

16. Nicholson. Teori-Teori Sosial. Jakarta : CV Rajawali. 2001.

17. Purwatiningsih R. Persepsi Masyarakat terhadap Peranan Puskesmas (Studi Deskriptif Kualitatif tentang Persepsi masyarakat mengenai peranan Puskesmas Jatinom dalam pelayanan kesehatan masyarakat di Kelurahan Krajan, Kecamatan Jatinom, Kabupaten Klaten). Skripsi. UNS. 2008; Vol. 1 (2) : 37-55.

18. Putra AW. Analisis Permintaan Penggunaan Layanan Kesehatan pada Rumah Sakit Umum Milik Pemerintah di Kabupaten Semarang. Skripsi. UNDIP. 2010; Vol. 4 (9) : 22-50.

19. Suhardi., Zahrol S dan Sutopo P. Analisis Faktor-Faktor yang Berpengaruh terhadap Kemauan Masyarakat Menjadi Peserta JPKM Mandiri di Wilayah Kota Salatiga. Jurnal Promosi Kesehatan Indonesia. 2014; Vol. 9 (1) : 55-74.

20. Putri PS., Nur A F dan Misnaniarti. Penerapan Marketing MIX melalui Pemanfaatan Pelayanan Kesehatan di Poliklinik Kebidanan dan Kandungan Rumah Sakit AR Bunda Prabumulih. Jurnal Ilmu Kesehatan Masyarakat. 2011; Vol. 2 (3) : 29-45

21. Puspita MA. Pemanfaatan Pelayanan Kesehatan oleh Peserta BPJS di Kelurahan Muktiharjo Kidul Semarang Tahun 2016. Skripsi. Univesitas Dian Nuswantoro. 2016.

22. Green. L., Kreuter M.W. Health Program Planning: An Educational and Ecological Approach. New York: McGraw-hill Comp. Inc. 2005.

23. Notoatmodjo S. Ilmu Prilaku Kesehatan. Jakarta : Rineka Cipta. 2010. 
24. Wulandari C., La OAIM dan Syawal KS. Faktor yang Berhubungan dengan Pemanfaatan Pelayanan Kesehatan di UPTD Puskesmas Langara Kecamatan Wawonii Barat Kabupaten Konawe Kepulauan Tahun 2016. Jurnal FKM Universitas Halu Oleo. 2016; Vol. 2 (5) : 13-45.

25. Primanita A. Hubungan antara Persepsi Tentang Sakit dengan Pemanfaatan Pelayanan Kesehatan oleh Peserta Jaminan Kesehatan Masyarakat di Puskesmas Gunungpati Kota Semarang. Skripsi Universitas Negeri Semarang. 2011.

26. Indryani. Analisis Faktor-Faktor yang Berhubungan dengan Utilisasi Pelayanan Persalinan oleh Pasien Antenatal Care di Rumah Sakit Puri Cinere Tahun 2013. Skripsi UIN Syarif Hidayatullah Jakarta. 2013.

27. Thabrany H. Jaminan Kesehatan Nasional Edisi Kedua. Jakarta: Rajawali Pers. 2016. 